\title{
The Computational Method of Evaluation Range for Reserves of Mineral Deposits Covered with Surface Buildings
}

\author{
Bing Han and Qiang Fua \\ China National Institute of Standardization, Beijing, 100088, China
}

\begin{abstract}
Research on the proper method to make sure the evaluation range of mineral deposits covered with surface buildings plays an important role in reducing occupation of important mineral deposits and ensuring smooth implementation of building engineering. The criterion of certainty of evaluation range for mineral deposits covered with surface buildings is presented, the vertical plane method is adopted to calculate the frontiers of obstructive ridges on account of the mineral traveling angles which indicate the permitted values of groud deformation. The evaluation range of mineral deposits covered with the complanation engineering and linearity engineering are studied by means of examples. The research conclusion can offer some lessons for routing optimum design of construction object or mineral property reparation.
\end{abstract}

\section{Introduction}

Development of mineral deposits under building engineerings will has a influence on the constructions and the facility, and put personal security at risk. To make sure the security of building engineerings, obstructive ridge should be set up to forbid the development of mineral deposits in certain spacial scale, and that is the covered mineral deposits [1-3]. With the rapid development of the national economy, the construction scale of high speed railways, expressways and new city areas has been continuously expanded, and the quantity of occupied mineral deposits has increased year by year. The construction of numerous projects causes irrational occupation of large amounts of important mineral deposits and seriously affects their sustainable utilization and development [4-6]. Such characteristics of mineral deposits as huge potential values, non-renewability and uneven regional distribution determine that the occupation will bring about heavy and irreparable losses.

In order to find the balance between the engineering construction and the maintenance of mineral deposits, the necessity, economy and validity of resources taken over by building engineerings must be justified, and the precondition is that the evaluation scope of mineral deposits occupied should be confirmed [7-8]. The evaluation of the covered mineral deposits is relate to a lot of fields, such as geologic survey, mining technique and mineral exploitation, however, there is no corresponding technical norms for reserves evaluation as a guide, the technical approaches used in practice are all in a mess. Accordingly, the technical approaches for the evaluation scope of covered mineral deposits is particularly important.

\section{Confirmation of assessment range}

During surveying and evaluation of covered mineral deposits, the security preservation range of building engineerings should be ascertained on the basis of corresponding norms. The range consist of the requisitioned land area, work site and safety margin for guaranteeing construction and operation [9-10]. For punctiform or complanation projects, such as buildings, plants, converting stations, valve chambers, dams and mine compounds, the external frontiers of construction is commonly defined as the confine. To keep a certain distance from a polygonal or circular base is designated as the preservation scope. For linearity project such as expressway, railroad and gas pipeline, we should keep a certain distance from the both sides of project centerline, which is taken as the preservation scope, and for the punctiform and linearity conbined projects, the outerside linked line is taken as the preservation scope, see Figure 1.

The types of building engineerings are different, the needs for security distance for laws and regulations are different. Taking the gas pipeline project as an example, the relevant laws requires that the digging up, mining and bursting are not allowed within $1,000 \mathrm{~m}$ from the both sides of pipelines; bursting, seismic prospecting, excavation, testboring are not allowed within $200 \mathrm{~m}$ from the both sides pipeline and within $500 \mathrm{~m}$ surrounding auxiliary facilities, such as the pressure station, measuring station, pumping station, distribution substation, valve chamber, storage tank farm and so on.

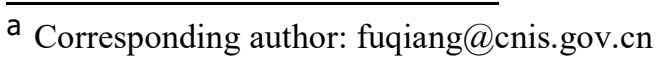




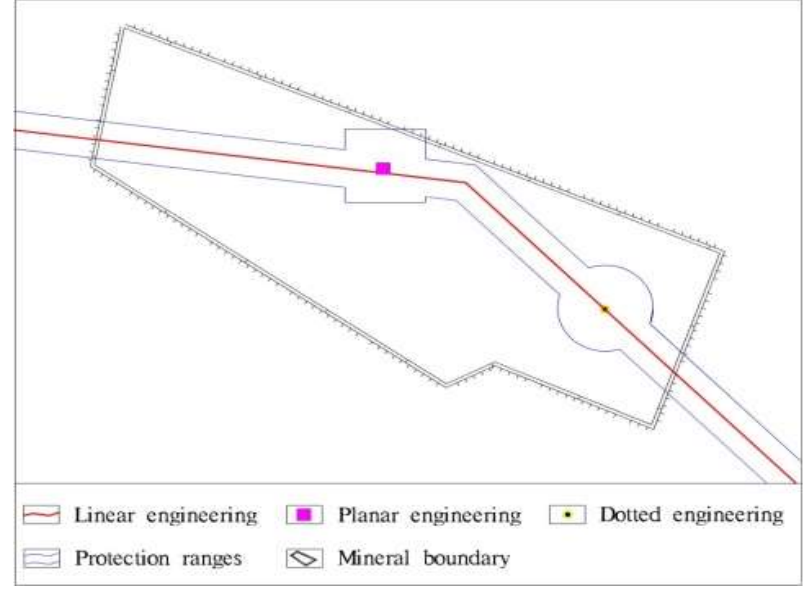

Figure 1. The covered range of mineral by building engineering.

For the preservation scope of mineral deposit outside neighbouring the engineering, the influnence of mineral deposit mining on the preservation belts and the security preservation scope beyond the engineering frontier should be considered, to make sure the occupied width of the construction item. After mineral deposit are exploited, caving zone will come into being in overburden rock stratum of mined-out area and a sinking basin will gradually taken shape, which will has an influence on ground constructions. The ground deformation indexes in sinking basin consist of sedimentation, inclination, buckling and displacement in horizontal direction. The ground deformation of mined-out area as is shown in Figure 2.

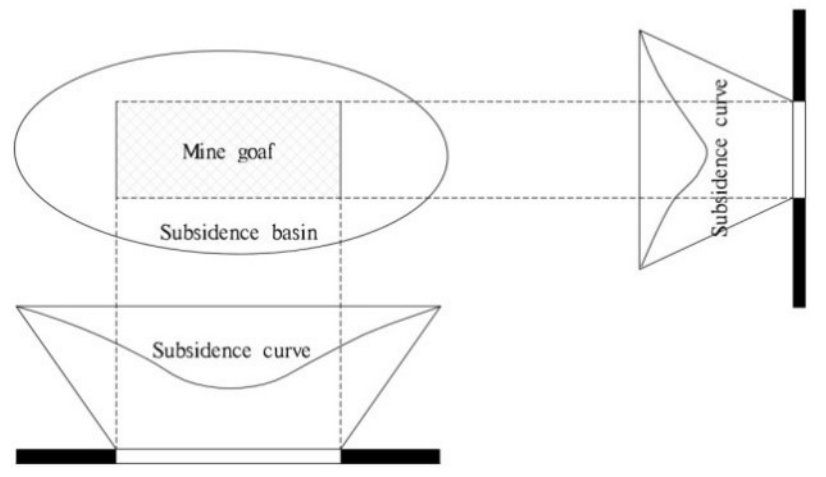

Figure 2. The ground deformation of mined-out area.

For the assessment of the covered mineral deposits, the frontier of obstructive ridges can be obtained if we make the traveling angle of rock layer projecting on the ichnography of coal bed. The evaluated value of frontier can be compared with the preservation scope from the relevant norms, and the values can be set according to the the maximum principle. So, the assessment range of mineral deposits occupied by construction projects can be ascertained.

\section{Boundary of obstructive ridges}

\subsection{Safety berm}

When obstructive ridges are estimated to make sure the preservation scope, the zone area surrounding ground structures is called as safety berm, and its width is related to the style and function of constructions. For example, the safeguard grade of coal mining is split into 1-4 levels based on significance and function of constructions and the aftereffect of coal mining. Every level is correspond to different the width of safety berm, see Table 1 .

Table 1. Width of safety berm of constructions.

\begin{tabular}{|c|c|}
\hline Levels of obstructive ridges & Width of safety berm (m) \\
\hline 1 & 24 \\
\hline 2 & 18 \\
\hline 3 & 12 \\
\hline 4 & 6 \\
\hline
\end{tabular}

\subsection{Traveling angle}

The permitted ground deformation is used to make sure the covered scope. In general, security scopes are ascertained based on traveling angle of overburden rock stratum. The traveling angle is an intersection angle with the waterline and the connecting line of the crisis deformation point and the frontier points of mining area. Traveling angle consists of unconsolidated formation angle $\varphi$, strike angle $\delta$, downhill direction angle $\gamma$ and uphill direction angle $\beta$. As is shown in Table $2 \sim 3$, the traveling angle $\varphi$ of unconsolidated formation and ground traveling angle is given.

Table 2. The traveling angle of unconsolidated formation.

\begin{tabular}{|c|c|c|c|}
\hline$h$ & Dried & Saturated & Shifting sand \\
\hline$<45 \mathrm{~m}$ & $40^{\circ}$ & $35^{\circ}$ & $28^{\circ}$ \\
\hline $45 \sim 60 \mathrm{~m}$ & $50^{\circ}$ & $45^{\circ}$ & $30^{\circ}$ \\
\hline$>60 \mathrm{~m}$ & $55^{\circ}$ & $50^{\circ}$ & $35^{\circ}$ \\
\hline
\end{tabular}

\subsection{Tangent plane method}

The frontier of obstructive ridges can be ascertained by tangent plane method. Drawing the profile lines perpendicular to strike and dip arround the center point of the protection frontier on the ichnography of coal bed, and the frontier point of obstructive ridges is ascertained on plane graph based to the landform, stratigraphic column and the chosen plane graph of traveling angle by projecting on the ichnography. These connecting lines are the scope of obstructive ridges. For other mineral species, we can draw several representative profiles based on the traveling angle, landform, geosphere and the properties of mineral species and evaluate frontier point of several characteristic points, which make it possibe to obtain the preservation scope by connecting the lines. 
Table 3. The general parameters of ground deformation.

\begin{tabular}{|c|c|c|c|c|c|}
\hline $\begin{array}{c}\text { Overburden } \\
\text { rock }\end{array}$ & $\begin{array}{c}\text { Compressive } \\
\text { strength/ } \mathrm{MPa}\end{array}$ & $\begin{array}{c}\text { Settlement } \\
\text { factor }\end{array}$ & $\begin{array}{c}\text { Traveling angle in } \\
\text { strike } \delta\end{array}$ & $\begin{array}{c}\text { traveling angle of } \\
\text { downhill direction } \gamma\end{array}$ & $\begin{array}{c}\text { traveling angle of } \\
\text { uphill direction } \beta\end{array}$ \\
\hline Hard & $>65$ & $0.28 \sim 0.55$ & $74 \sim 78^{\circ}$ & $74 \sim 78^{\circ}$ & $\delta$ - $(0.6 \sim 0.7) \alpha$ \\
\hline Medium & $35 \sim 65$ & $0.55 \sim 0.85$ & $67 \sim 74^{\circ}$ & $67 \sim 74^{\circ}$ & $\delta-(0.5 \sim 0.6) \alpha$ \\
\hline Soft & $<35$ & $0.85 \sim 1.2$ & $60 \sim 67^{\circ}$ & $60 \sim 67^{\circ}$ & $\delta-(0.4 \sim 0.5) \alpha$ \\
\hline
\end{tabular}

\section{Case analysis}

\subsection{Complanation project}

The tangent plane A-A' is plotted along the strike of coal bed, so we can get the profile of A-A' along Z-direction. As in shown in Figure 3-1 and 3-2.

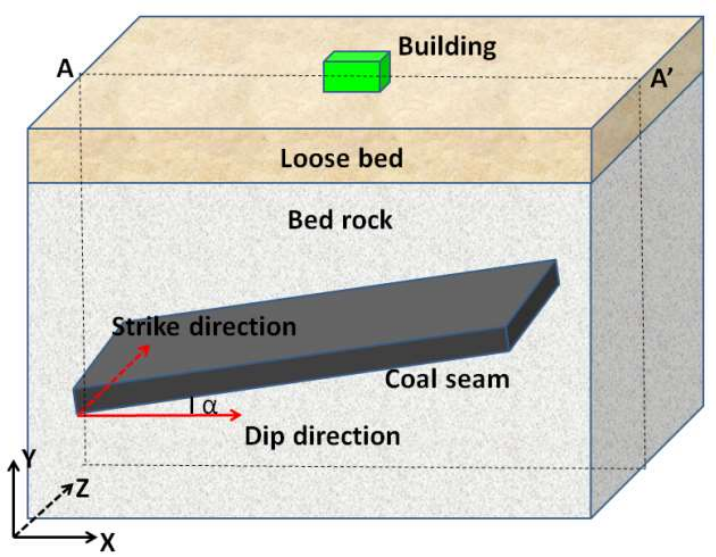

$3-1$

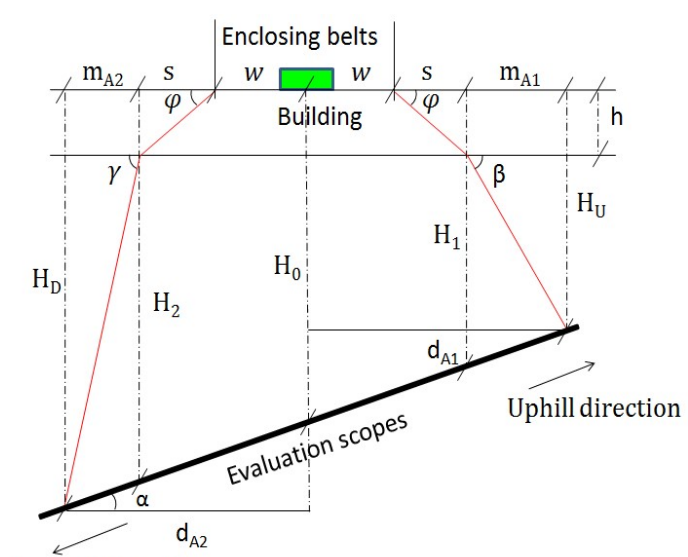

Downhill direction

$3-2$

Figure 3. The diagrammatic sketch of coal bed covered by a complanation project (Z-axis view).

As shown in Figure 3-2, we can obtain the covered scopes: $d_{A 1}, d_{A 2}$, which represent respectively the direction along uphill and downhill, as follow

$$
d_{A 1}=w+h \cot \varphi+\left(H_{1}-h\right) /(\tan \beta+\tan \alpha)
$$

$$
d_{A 2}=w+h \cot \varphi+\left(H_{2}-h\right) /(\tan \gamma-\tan \alpha)
$$

$H$ is the vertical depth, in accordance with the differentia between coal bed and land surface, we have

$$
\begin{gathered}
H_{1}=H_{0}-(w+s) \tan \alpha \\
H_{2}=H_{0}+(w+s) \tan \alpha \\
H_{U}=m_{A 1} \tan \beta+\mathrm{h} \\
H_{D}=m_{A 2} \tan \gamma+\mathrm{h}
\end{gathered}
$$

The tangent planes B-B' and C-C' are plotted at $d_{A 1}$ and $d_{A 2}$ from the two flanks of construction, so we can obtain the profiles of B-B' and $\mathrm{C}-\mathrm{C}^{\prime}$ respectively. As in shown in Figure 4-1 and 4-2.
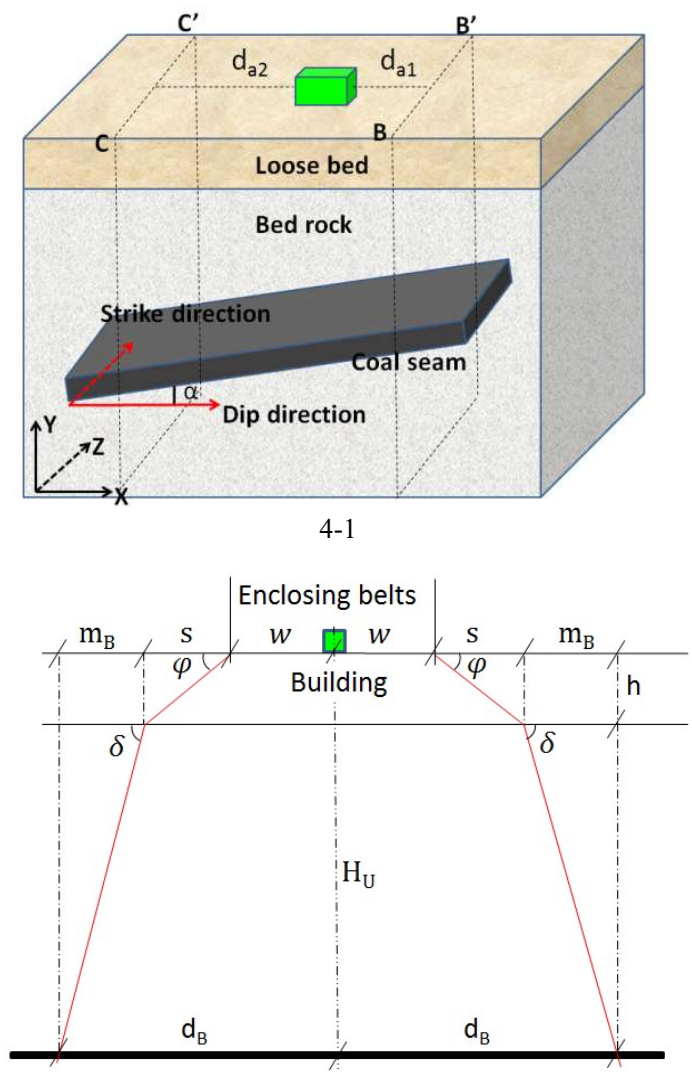

Evaluation scopes

4-2

Figure 4. The diagrammatic sketch of coal bed covered by a complanation project (X-axis view). 
As shown in Figure 4-2, we can obtain the covered scope $d_{B}$, as below

$$
d_{B}=w+h \cot \varphi+\left(H_{U}-h\right) \cot \delta
$$

The covered scope $d_{C}$ can be written as

$$
d_{C}=w+h \cot \varphi+\left(H_{D}-h\right) \cot \delta
$$

If we project the circumference of construction onto the ichnography of coal bed, we can draw a ladder-shaped area, which is the assessment range of coal bed occupied by complanation project. As shown in Figure 5,

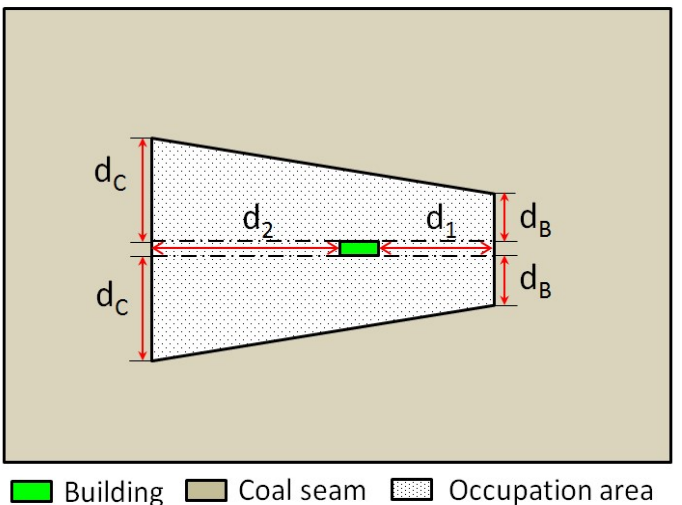

Figure 5. The assessment range of coal bed occupied by complanation project.

\subsection{Linearity project}

The solution methods of covered scope for linearity project is analogy to the complanation project, we need to plot some tangent planes and evaluate them respectively, as shown in Figure 6-1. In view of the distinguishing feature of linearity project, the influence of included angle between axial direction of project and trend of coal bed on evaluating of covered scope should be taken into consideration. We have introduced $\theta$ into the evaluating of traveling angle $\beta$ and $\gamma$, as shown in Figure 6-2, the covered scope can be written as

$$
\begin{gathered}
d_{A 1}=w+h \cot \varphi+\left(H_{1}-h\right) /\left(\tan \beta^{\prime}+\tan \alpha\right) \\
d_{A 2}=w+h \cot \varphi+\left(H_{2}-h\right) /\left(\tan \gamma^{\prime}-\tan \alpha\right) \\
\beta^{\prime}=\cot ^{-1} \sqrt{\sin ^{2} \theta \cot ^{2} \delta+\cos ^{2} \theta \cot ^{2} \beta} \\
\gamma^{\prime}=\cot ^{-1} \sqrt{\sin ^{2} \theta \cot ^{2} \delta+\cos ^{2} \theta \cot ^{2} \gamma}
\end{gathered}
$$

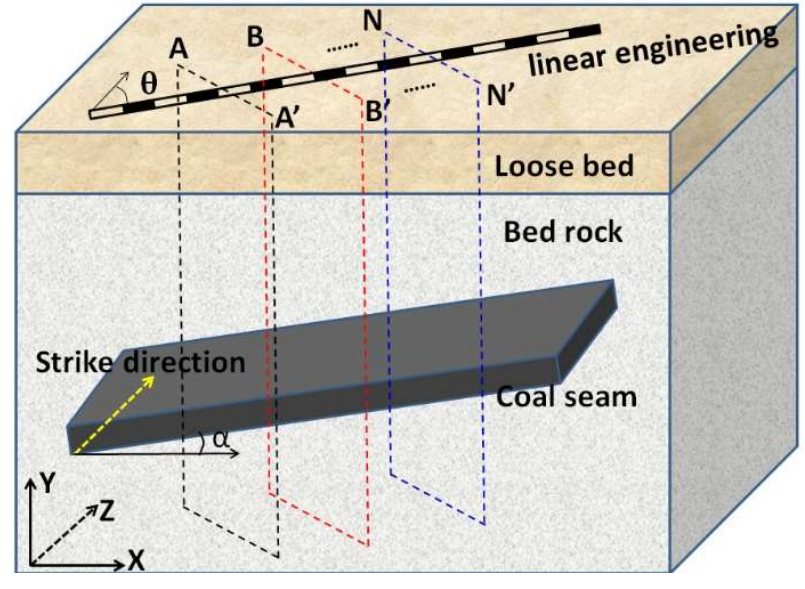

$6-1$

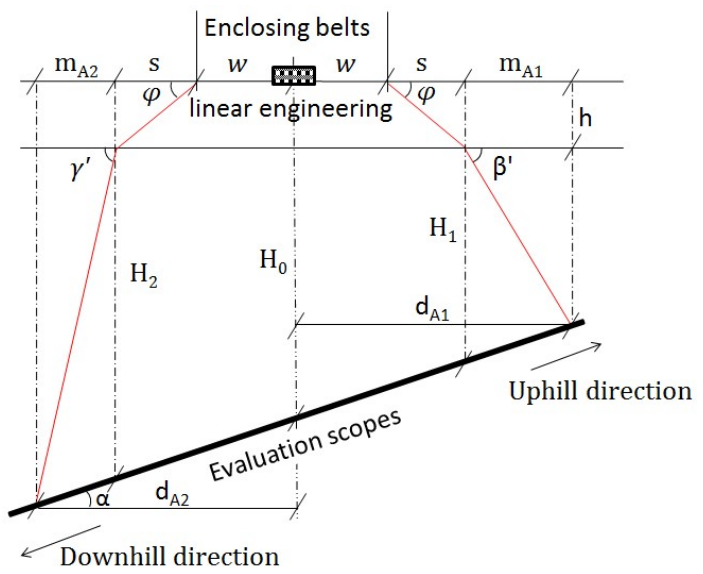

$6-2$

Figure 6. The diagrammatic sketch of coal bed occupied by linearity project.

After the coverd scope of other tangent planes have been evaluated in accordance with the above methods, we can project them onto the ichnography of coal bed, which make it possible to calculate the assessment range of coal bed occupied by linearity project, as shown in Figure 7.

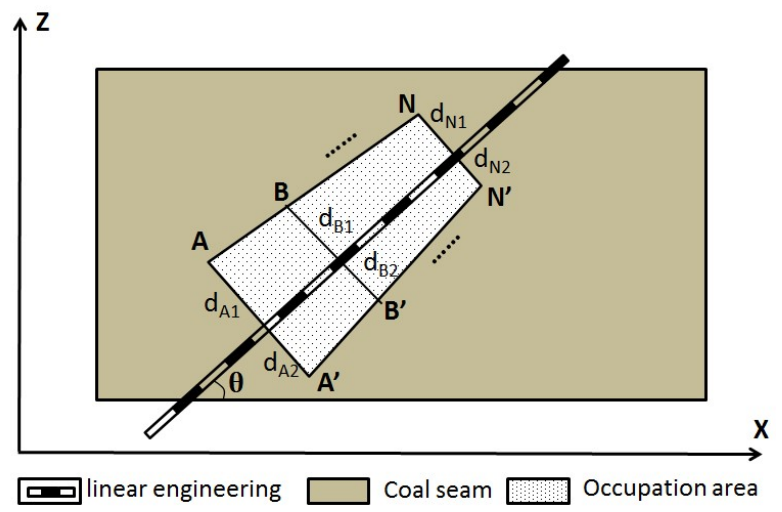

Figure 7. The assessment range of coal bed occupied by linearity project. 


\section{Conclusions}

The tangent plane method is applied to make sure the assessment range of the covered mineral deposits by projecting the region based on the perpendicular line of traveling angle onto land. Compared with the conventional method, for example, the mineral deposits under the building engineerings is regarded as the covered resource, the tangent plane method has characteristic of high accuracy, and it is contribute to the selection and comparison of route schemes.

The calculation instances discussed above are directed against the one-layer coal mining. For multilayer coal mining, because the obstructive ridge frontiers of every layer are increasing gradually with the extension of traveling angle of rock stratum, two flanks of frontier for the nethermost coal layer are regarded as the maximum covered scope. Consequently, besides the coal resources covered directly by constructions on every layer, the indirect mining influence of the nethermost layer on upper ones should be considered.

\section{References}

1. L. S. Jin, J. S. Mu, Specifications for Coal Pillar Preservation and Compressed Coal Mining for Buildings, Water Bodies, Railways and Main Shafts. China Coal Industry Publishing House, Beijing (2000)

2. D. A. Singer, Progress in Integrated Quantitative Mineral Resource Evaluations. Ore Geology Reviews, 38(3): 242-250 (2010).
3. W. D. Wang, Y. P. Li, Error of Geological Ore Block Method for Coal Resources/Reserves Estimation and Improvement Method. Coal Geology \& Exploration, 42(5): 1-3 (2014).

4. X. Luoa, R. Dimitrakopoulos, Data-driven Fuzzy Analysis in Quantitative Mineral Resource Evaluation. Computers and Geosciences, 29(1): 3-13 (2003).

5. D. H. Liu, Y. Q. Xing, D. D. Zhai, Technique Research on Mineral deposits Overlaid by Building engineerings-Taking General Main Canal in Phase I Project of the South-to-North Water Transfer Middle Line as An Example. Henan Science, 28(9): 1182 1188 (2010).

6. K. Q. Li, Q. Zhang, F. Wu, Accounting Method of the Environmental Reparation Value in Mineral deposits Developing. Advanced Materials Research, 807-809: 2421-2426 (2013).

7. S. H. Zhang, Research on Investigation and Evaluation Methods of Mineral deposits Overlaid by Building engineerings. Resources Environment \& Engineering, 26(3): 278-280 (2012).

8. X. B. Yue, Z. P. Shuai, J. X. Wang, Research on Evaluation Methods of Mineral deposits Overlaid by Building engineerings. Yangtze River, 44(6): 44-46 (2013)

9. Y. H. Meng, The estimation of mineral deposits reserves in the coal mine building engineering-Taking the building engineering of a coal mine industrial square as an example. Shandong Coal Science and Technology, 11, 34-36 (2016).

10. X. D. Liu, S. H.Zuo, H. S. Cao, Determination of the protective coal pillar in pressed mineral deposits estimation. Shaanxi Meitan, 1, 89-91 (2015). 